\title{
Preparation of Dithienylethene with Amino Groups, and Photochromic Behavior in Langmuir-Blodgett Film of the Amphiphilicdithienylethene
}

\author{
Tetsuzo Fujise, Michinori Takeshita, Koichi Sakaguchi, Masanao Era* \\ Department of Chemistry and Applied Chemistry, Saga University, Saga, Japan \\ Email:*era@cc.saga-u.ac.jp
}

Received March 22, 2013; revised May 10, 2013; accepted May 26, 2013

Copyright (C) 2013 Tetsuzo Fujise et al. This is an open access article distributed under the Creative Commons Attribution License, which permits unrestricted use, distribution, and reproduction in any medium, provided the original work is properly cited.

\begin{abstract}
We successfully synthesized dithienylethene with amino groups. Then, we successfully prepared Langmuir-Blodgett (LB) films of the dithienylethene having ammonium cation group when dodecyl benzene sulfonic acid was employed as an anionic counter ion. From X-ray diffraction profiles, however, it was demonstrated that they did not form well-defined layered structure; X-ray diffraction peaks were much broadened. Photochromic behavior was confirmed in the LB films. Unfortunately, the LB films were not so stable; photochromic reaction was observed only several times in the LB films.
\end{abstract}

Keywords: Amphiphilic Dithienylethene; Langmuir-Blodgett Film; Photochromic Material; Dodecyl Benzenesulfonic Acid

\section{Introduction}

Thermally irreversible (p-type) photochromic compounds are a promising candidate for optoelectronic devices, for example, optical memory [1], holography [2], photooptical switching [3], and display [4,5]. In particular, dithienylethenes are well-known to be very thermally stable in solution $[6,7]$. In addition, they have been reported to exhibit stable photochromism in crystal state because the change of their molecular structure is very small during photo chromic reaction, so that their photochromic reaction occurs even in crystal state [8]. Therefore, they are promising for the device applications.

For practical use as memory media, however, it is indispensable that the materials can form uniform film. Langumuir-Blodgett (LB) technique is a powerful tool to prepare uniform thin films whose film structure is controlled at a monomolecular level. If one can prepare LB film with multilayer structure consisting of different photo chromic compounds, multiple optical memory will be attained. Until now, few such studies have been conducted [9]. In these studies, however, they employed photochromic compounds which have large molecular structure change during their photochromic reaction, for example, azobenzene, spyropyran and so on [10-13]. The

\footnotetext{
"Corresponding author.
}

employment of the molecules with large molecular structure change during photochromic reaction is not appropriate to the application to rewritable optical memory since large molecular structure change disrupt the well-defined film structure. As a first step of aiming construction of multiple optical memory, in this study, we prepared LB film having dithienylethene chromophore, and evaluated its film structure and photochromic behavior. Here, we recited the reasons why we employed the thieny lethene chromophore as follows,

1) Dithienylethenes have small structure change during photochromic reaction; the photochromic reaction was observed even in their crystals $[8,14]$;

2) They are thermally stable, in other words, they are not converted thermally to their initial non-coloured state after their conversion to coloured state by irradiation of UV light $[15,16]$;

3) They have very fast response time of $2-3$ ps for photochromic reaction [17];

4) They are also chemically stable; phochromic reaction cycle number is more than $104[18,19]$.

In the previous work [20], S. Abe et al. demonstrated that the LB films of dithienylethene derivatives having long alky chain are successfully prepared when they are mixed with tripalmitin and that stable photochromic re- 
action in the LB films was confirmed by the change in fluorescence intensity caused by energy transfer from donor layer of a cyanine dye, which was deposited in the same LB films, to the dithienylethene layer when UV light and vis light were altermately irradiated. However, their LB films were mixed with other LB film forming amphiphile (tripalmitin and cadomium arachidate). Because the dithienylethene derivatives have weak hydrophilicity, in our consideration, the derivatives may require the mixing with the stable LB film forming amphiphiles for formation of stable Langmuir monolayer. The dilution of photochromoic spieces by mixing with inert LB film forming materials is not used to apply the LB film to high density optical memory. So that, by employing a photochromic amphiphile consisting of a cationic dithienylethene and anionic counter with long alkyl chain, we expected to form a stable LB film because of their balanced amphiphilicity for LB film formation. Further, if anionic counter ions with functional chromophore are employed, it is expected to construct multifunctional photochromic devices. In this paper, we report the LB film formation of the amphiphilic dithienylethene and its photochromic behavior.

\section{Experiments}

Figure 1 shows systhetic scheme of dithienylethene having ammonium bromide groups and molecular strcuture of dodecyl benzencsulfonic acid (DBS). The dithienylethene compoumd with ammonium group (DTE) and DBS were dissolved in chloroform (molar ratio; DTE: $\operatorname{DOS}=1: 2$ ). By use of exstraction using $\mathrm{H}_{2} \mathrm{O}$, then, unwished inorganic materials were pruned from the chloroform solution. Finally, dithienylethene having dodecyl benzenesulfonic acid as an anionic counter ion was obtained by evaporation of the solvent.
Non-coloured dithienylethene has two types of structure, i.e. anti-pallarel and pallarel. Since the pallarel structure does not exhibit photochromic reaction [17], the obtained dithienylethene having long dodecyl benzenesulfonic acid was sufficiently converted to its coloured species by irradiation of UV light passed through UV-pass filter (Siguma Koki, UTVAF-34U) from xenon lamp (Atago Bussan Co., LTD., XC-300) after dissolved in chloro- form (conc. $=10^{-4} \mathrm{M}$ ); this means that we irradiated UV light until their absorption spectra were not changed. Monolayers of the dithienylethene were spread on a deionized water from the chloroform solution. The monolayers were deposited by the conventional Langmuir-Blodgett (LB) technique. The LB film preparation procedure was carried out in dark room. When the coloured structure in the obtained LB film were converted to non-color structure, we used visible light passed through sharp cut filter (Sigma Koki, SCF-50S-480Y) and IR cut filter (Sigma Koki, HAF-50S-15H) from the xenon lamp. For evaluation of reversible photochromic behavior in the LB films, above-mentioned the UV and visible light sources were employed.

\section{Results and Discussion}

Figure 2 shows surface pressure-area isotherm of the dithienylethene having long dodecyl benzenesulfonic acid as an anionic counter ion at $303 \mathrm{~K}$ on deionized water of $>1 \mathrm{M} \Omega \cdot \mathrm{cm}$ (MILLIPORE Milli-DI) as a subphase. The isotherm was measured using a coloured species which was converted by enough UV light irradiation. The isotherm exhibits very expanded region (from 1 $\mathrm{nm}^{2} /$ molecules to $0.8 \mathrm{~nm}^{2} /$ molecules) and through the plateau region, condensed region around $0.15 \mathrm{~nm}^{2} /$ molecule is observed. We could not prepare LB film in the expanded region. In the condensed region, however, we

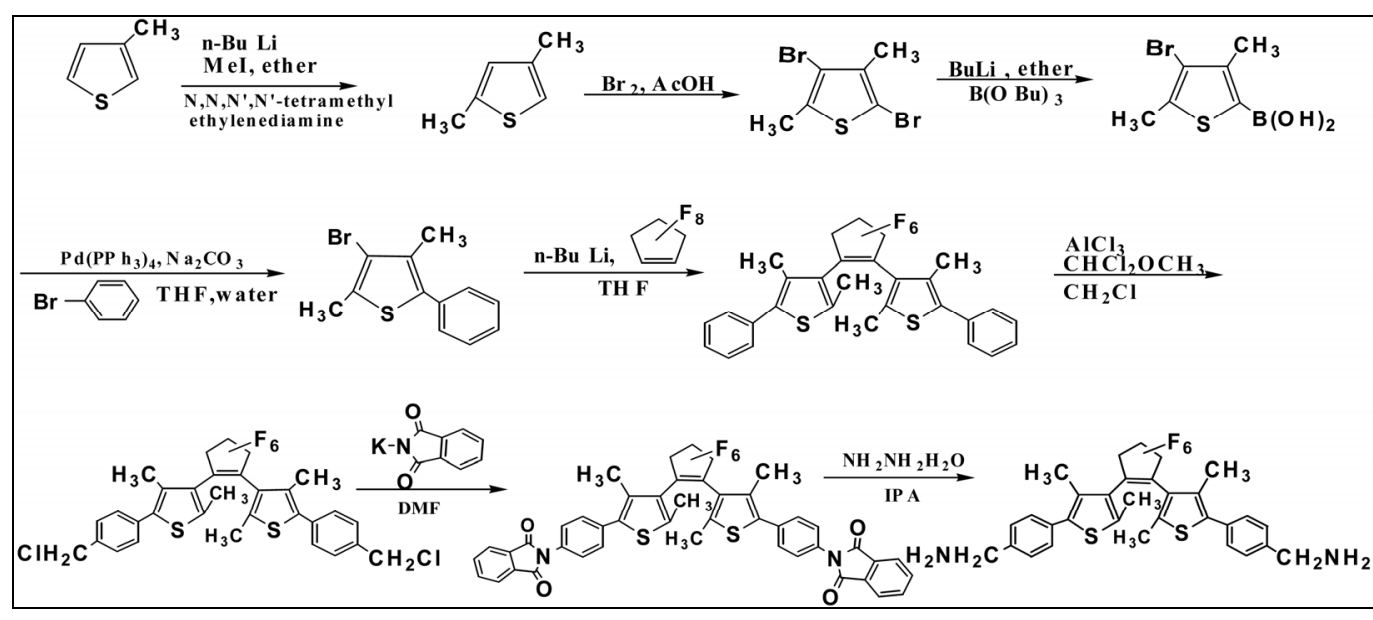

(a)

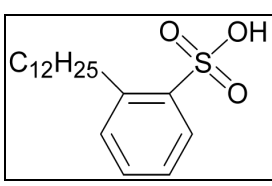

(b)

Figure 1. (a) Systhetic scheme of dithienylethene having ammonium bromide groups, and (b) molecular strcuture of dodecyl benzencsulfonic acid. 


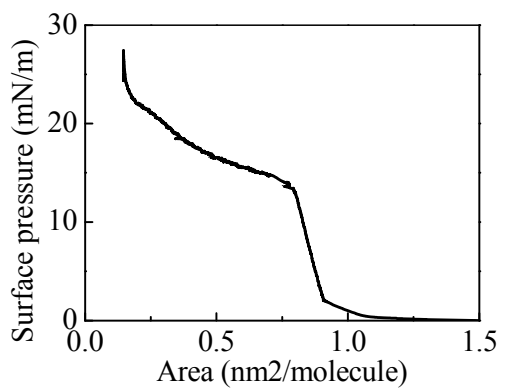

Figure 2. Surface pressure are isotherm of dithienylethene having long dodecyl benzenesulfonic acid as an anionic counter ion.

could prepare the LB films of dithienylethene having long dodecyl benzenesulfonic acid as an anionic counter ion.

Figure 3 shows X-ray diffraction profiles of as-deposited film, coloured film and non-coloured films. All $\mathrm{X}$-ray diffraction profiles are very broadened, demonstrating the well-defined layered structure did not formed. From the broadened peaks, layer spacing of the LB films were estimated to be $12.4 \mathrm{~nm}$. The value is very small in comparison of molecular length of dodecyl benzenesulfornic acid in which aklyl chain was assumed to form all zigzag trans-conformation. The result demonstrates that we did not obtain the LB film with well-defined layer structre; their orderliness is very low and they have a lot of defect as a result of a huge variety of alkyl chain conformation in the LB films.

Figure 4 (a) shows absorption spectra of as-deposited film, coloured film and non-coloured films. As-deposited films are peaking around $550 \mathrm{~nm}$. Its colour was violet. By visible light irradiation, the as-depsited film was converted to non-coloured film. Further, by UV light irradiation, the non-coloured film was converted to coloured film. Unfortunately, reversibility of photochromic reaction in the LB films was not good; only several times photochromic reaction was observed in the LB films (Figure 4(b)). On the contrary, reversibility of thienylethene derivative and dodecyl benzenesulfonic acid, in which were dissolved, was very good. The absorbance is almost constant during the repetition photochromic reaction.

As the result of X-ray diffraction measurent, the LB films did not form well-defined layered structure and they have a lot of defect. Such not well-defined and lowdense structure facilitates penetration of oxygen gas into the LB films. The result suggests that disapperance of photochromic performance in the LB films [21] is most likely to be due to degradation of the dithienylethene by solfonic acid-catalyzed oxidization with oxygen, which penetrated into the LB film, dodecyl benzene solfonic acid has high acidity and because the photochromic reaction was carried out in the air. On the other hand, in the solution, the thienylethene molecules and dodecyl benzenesulfonic acid molecules are not so around each other;

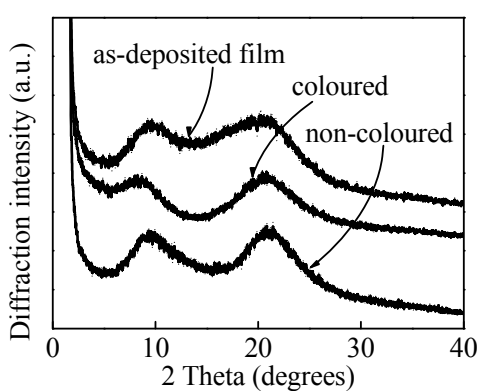

Figure 3. X-ray diffraction profiles of as-deposited film, coloured film and non-coloured films.

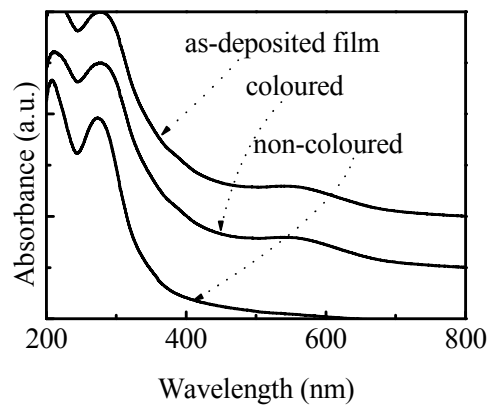

(a)

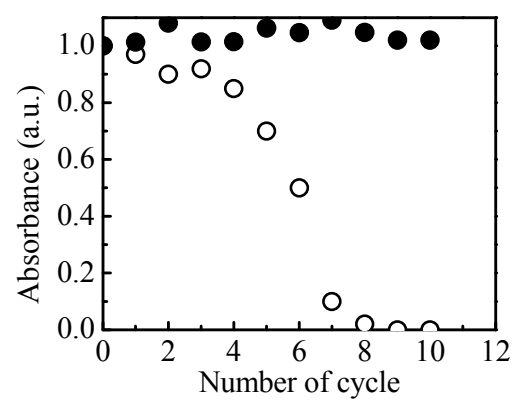

(b)

Figure 4. (a) Absorption spectra of as-deposited film, coloured film and non-coloured films, and (b) reversibility of the photochromic reaciton in the $\mathrm{LB}$ film (open circle): absorbance at $550 \mathrm{~nm}$ after irradiation UV light and fulled circle: Absorbance at $550 \mathrm{~nm}$ after irradiation UV light and that of the thienylethene derivative and dodecyl benzene solfonic acid in chroloform. The ordinate is normalized by absorbance of as-deposited LB film. In the case of solution, the ordinate is normalized by first coloured solution.

accordingly, the degradation as observed in the LB films was not ocuured.

\section{Summary}

In summary, we successfully prepared Langmuir-Blodgett (LB) films consisting of amphiphilic cationic dithienylethene by employing dodecyl benzenesulfonic acid as an anionic counter ion. Form X-ray diffraction profiles, however, it was demonstrated that they did not well defined layered structure. Photochromic behavior was confirmed in the LB films. However, the LB films 
were not so stable in the photochromic reaction; only several times photochromic reaction cycle was observed in the LB films.

For well-defined layered structre in LB film, we need to use counter anion having longer alkylchain. For the enhancement of the stability of photochromic behavior, we need to perform photochromic reaction in inert atmosphore or deposite passivation layer on the LB films to avoid penetration of oxygen; in S. Abe's work in which they demonstrated stable photochromic reaction [20], their photochromic LB films were actually arachidic acid layerd which may play the role of passivation. In addition, the employment of week acidity counter anion with long alkyl chain such as arachidic adid is available to prevent acid-catalized degradation and enhance the photochromic performance.

\section{REFERENCES}

[1] M. Irie, "Photo-Reactive Materials for Ultrahigh Density Optical Memory," Photo-Reaction Materials Ultfahigh Density Optcal Memories, 1994, pp. 1-12.

[2] K. Matsuda and M. Irie, "A Diarylethene with Two Nitronyl Nitroxides: Photoswitching of Intramolecular Magnetic Interaction," Journal of the American Chemical Society, Vol. 122, No. 30, 2000, pp. 7195-7201. doi: $10.1021 / \mathrm{ja} 000605 \mathrm{v}$

[3] Z. P. Tomg, G. Liu and C. Shiqiang, "Synthesis, Properties and Application in Optical Memory of a New Photochromic Diarylethene Based on a Chlorine Atom," Advanced Material Research, Vol. 455-456, 2012, pp. 25-28. doi:10.4028/www.scientific.net/AMR.455-456.25

[4] J. Yao, K. Hashimoto and A. Fujishima, "Photochromism Induced in an Electrolytically Pretreated Mo03 Thin Film by Visible Light," Nature, Vol. 355, No. 6361, 1992, pp. 624-626. doi:10.1038/355624a0

[5] C. Behinger, S. Ferrer, A. Zaban, J. Sprague and B. A. Gregg, "Photoelectrochromic Windows and Displays," Nature, Vol. 383, No. 6601, 1996, pp. 608-610. doi: $10.1038 / 383608 \mathrm{a} 0$

[6] K. Morimitsu, K. Shibata, S. Kabakake and M. Irie, "Dithienylethenes with a Novel Photochromic Performance," Journal of Organic Chemistry, Vol. 67, No. 13, 2002, pp. 4574-4578. doi:10.1021/jo020114o

[7] M. K. Hossain, M. Takeshita and T. Yamato, "Synthesis and Photochromic Properties of a Dithia-Dithienylethenophane," Tetrahedron Letters, Vol. 46, No. 3, 2005, pp. 431-433. doi:10.1016/j.tetlet.2004.11.090

[8] H. Ohara, M. Morimoto and M. Irie, "Photochromism of Dithienylethene Single Crystals Having Anthracene Substituents," Photochemical \& Photobiological Sciences, Vol. 9, No. 8, 2010, pp. 1079-1081. doi:10.1039/c0pp00083c

[9] V. A. Barachevsky, M. M. Krayushikin, V. V. Kyiko and E. P. Grennikov, "Light-Sensitive Organic Recording Media for 3D Optical Memory," Physica Status Solidi, Vol. C8, 2011, p. 2841.

[10] T. Tachibaha, H. Shibata and M. Matsumoto, "Effect of
Fabrication Conditions on the Structures and Photoreactions of Langmuir-Blodgett Films of Amphiphilic Spiropyran," Transactions of the Materials Research Society of Japan, Vol. 33, No. 1, 2008, p. 115.

[11] R. Azumi, K. Kakiuchi and M. Matsumoto, "Fabrication and Efficient Photochromism of the Mixed LangmuirBlodgett Films of a Water-Miscible Azobenzene Amphiphile and Long-chain Alkylammoniums," Chemistry Letters, Vol. 33, No. 2, 2003, pp. 172-173.

doi:10.1246/cl.2004.172

[12] H. Tachibana, T. Yamada, H. Sakai, M. Abe and M. Matsumoto, "Self-Organization and Photochromic Reaction in the Langmuir-Blodgett Films of Amphiphilic Azobenzene Complexed with Polyallylamine," Molecular Crystals and Liquid Crystals Science and Technology. Section A. Molecular Crystals and Liquid Crystals, Vol. 345, No. 1, 2000, pp. 119-124. doi:10.1080/10587250008023905

[13] V. M. Anisimov, A. M. Vinogradov, E. I. Kuzinelsov, S. A. Senakhov and M. V. Alfimov, "Kinetic Nonequivalence of Spiropyran Molecules during Their Photochromic Conversions in Langmuir-Blodgett Layers," Bulletin of the Academy of Sciences of the USSR, Vol. 9, 1991, p. 2018.

[14] M. Irie and K. Sayo, "Temperature Dependence of the Rate Constants for Oxidation of Organic Compounds by Peroxyl Radicals in Aqueous Alcohol Solutions," Journal of Chemical Physics, Vol. 96, No. 2, 1992, pp. 767-770. doi: $10.1021 / \mathrm{j} 100181 \mathrm{a} 045$

[15] M. Irie, "Photochromism of Diarylethene Molecules and Crystals," Proceedings of the Japan Academy, Series B, Vol. 86, 2010, p. 472.

[16] N. Tami, T. Saika, T. Shimidzu and M. Irie, "Femtosecond Dynamics of a Thiophene Oligomer with a Photoswitch by Transient Absorption Spectroscopy," Journal of Chemical Physics, Vol. 100, No. 12, 1996, pp. 46894692. doi:10.1021/jp953181d

[17] M. Irie, "Diarylethenes for Memories and Switches," Chemical Review, Vol. 100, No. 5, 2000, pp. 1685-1716. doi:10.1021/cr980069d

[18] M. Hanazawa, R. Sumiya, Y. Horikawa and M. Irie, "Thermally Irreversible Photochromic Systems. Reversible Photocyclization of 1,2-Bis(2-methylbenzo[b]thiophen-3-yl)perfluorocyclocoalkene Derivatives," Journal of the Chemical Society, Chemical Communications, Vol. 3, 1992, pp. 206-207. doi:10.1039/c39920000206

[19] K. Uchida, Y. Nakayama and M. Irie, "Thermally Irreversible Photochromic Systems. Reversible Photocyclization of 1,2-Bis(benzo[b]thiophen-3-yl)ethene Derivatives," Bulletin of the Chemical Society of Japan, Vol. 63, No. 5, 1990, pp. 1311-1315. doi:10.1246/bcsj.63.1311

[20] S. Abe, K. Uchida, I. Yamazaki and M. Irie, "FatigueResistance Property of Diarylethene LB Films in Repeating Photochromic Reaction," Langmuir, Vol. 13, No. 20, 1997, pp. 5504-5506. doi:10.1021/la970555g

[21] Z. Emo, I. Yulidiz, B. Gorodetsky, F. M. Raymo and N. R. Branda, "Optical Control of Quantum Dot Luminescence via Photoisomerization of a Surface-Coordinated, Cationic Dithienylethene," Photochemical \& Photobiological Sciences, Vol. 9, 2010, pp. 249-253. doi:10.1039/b9pp00115h 